\title{
Systems chemistry: from chemical self-replication to trisoligo-based nanoconstruction
}

\author{
Günter von Kiedrowski \\ From 5th German Conference on Cheminformatics: 23. CIC-Workshop \\ Goslar, Germany. 8-10 November 2009
}

Self-replication is one of the major principles without life could not exist. The emergence of self-replicating systems on the early earth is generally believed to have taken place before the advent of instructed protein synthesis based on a complex translation machinery. Whether the origin of self-replication is identical to the origin of the hypothetical RNA world or whether it existed at an earlier stage of evolution is an open question that has stimulated chemists to search for chemical systems capable of making copies of itselves via autocatalytic reactions. As self-replication means autocatalysis plus information transfer, the reaction products must necessarily be able to store more structural information than their precursors. Templating as a means to transfer structural information has been exploited since the first successful example of a chemical self-replicating system almost two decades ago [1]. Today we have a broad variety of such systems employing oligonucleotides, peptides, and small organic molecules as templates and autocatalytic [1-3], cross-catalytic [4], collectively autocatalytic and non-autonomous (stepwise) schemes of self-replication [5].

A link between the chemical self-replication and nanotechnology was first pointed out by G.M.Whitesides in his debate with Drexler. The ribosome is an example for a nanomachine which may be viewed as a three-dimensionally defined array of 51 modular proteins positioned by the rRNA scaffold. Biomimetic approaches towards the 3D-nano-scaffolding of modular functions may be based on trisoligonucleotides [6], viz. synthetic 3-arm junctions in which the 3 '-ends of three oligonucleotides are connected by a suitable linker. We report on trisoligos as building blocks for the noncovalent construction of nanoobjects. Kinetic control - applied by rapid

Correspondence: kiedro@rub.de

Lehrstuhl für Organische Chemie I - Bioorganische Chemie, Ruhr-Universität, Universitätsstrasse 150, 44780 Bochum, Germany cooling during self-assembly - was found to favor small and defined nano-structures instead of large polymeric networks [6]. Maximal instruction was employed as design principles to generate noncovalent 3D-nanoobjects in which both, the topology and the geometry is defined [7]. Examples include dodecahedral nano-scaffolds composed from 20 trisoligos each bearing three individually defined sequences [8]. It was demonstrated that the connectivity information in the nano-scaffold junctions can be copied by chemical means [9]. Chemical copying schemes may be seen in conjunction with "surface-promoted replication and exponential amplification of DNA analogues" (SPREAD) [5]. Applications of such scaffolds include the positioning of modular functions such as multidentate thioether-based gold cluster labels (RUBiGold) [10] which have been tailored for monoconjugability and thermostability.

My lecture will introduce chemical self-replication and multicomponent assembly as facets of systems chemistry $[3,11,12]$ - a nascent field which understands itself as the bottom-up pendant of systems biology towards synthetic biology [14]. The field is clearly inspired by the origin-of-life problem but goes beyond traditional prebiotic chemistry in its mission towards a quantititive dynamic understanding of complex reaction networks with autocatalytic components. Software tools like our SimFit and kinetic NMR titration [2] may significantly help to decipher signatures of interesting dynamic phenomena such as self-replication, chiral symmetry-breaking, and metabolic autocatalysis found in organic [13] and biomolecular [12] reaction systems.

\section{Published: 4 May 2010}

\section{References}

von Kiedrowski G: Angew Chem Int Ed Engl 1986, 25:932.

Stahl I, von Kiedrowski G: J Am Chem Soc 2006, 28:14014-14015.

Kindermann M, et al: Angew Chem 2005, 117:6908-6913. 
4. Sievers D, von Kiedrowski G: Nature 1994, 369:221.

5. Luther A, Brandsch R, von Kiedrowski G: Nature 1998, 396:245.

6. Scheffler M, et al: Angew Chem Int Ed Engl 1999, 38:3312

7. von Kiedrowski G, et al: Pure Appl Chem 2003, 75:609.

8. Zimmermann J, et al: Angew Chem 2008, 120:3682-3686.

9. Eckardt L, et al: Nature 2002, 420:286.

10. Pankau WM, Mönninghoff S, von Kiedrowski G: Angew Chem 2006, 118:1923-1926.

11. Stankiewicz J, Eckardt LH: Angew Chem 2006, 118:350-352.

12. Hayden EJ, von Kiedrowski G, Lehman N: Angew Chem 2008, 120:8552-8556.

13. Kramer D, Pankau WM, von Kiedrowski G.

14. MoU

doi:10.1186/1758-2946-2-S1-01

Cite this article as: von Kiedrowski: Systems chemistry: from chemical self-replication to trisoligo-based nanoconstruction. Journal of

Cheminformatics 2010 2(Suppl 1):01.

\section{Publish with ChemistryCentral and every scientist can read your work free of charge}

"Open access provides opportunities to our colleagues in other parts of the globe, by allowing anyone to view the content free of charge." W. Jeffery Hurst, The Hershey Company.

- available free of charge to the entire scientific community

- peer reviewed and published immediately upon acceptance

- cited in PubMed and archived on PubMed Central

- yours - you keep the copyright

Submit your manuscript here:

http://www.chemistrycentral.com/manuscript/<smiles>c1ccccc1</smiles>
ChemistryCentral 